\title{
O CELTISMO CUNQUEIRANO: RE(IN)VENTANDO O MITO E 0 POSTERIOR DESENCANTO NO FARO DE VIGO (1961-1981)
}

Rubén Jarazo Álvarez

I. U. Estudos Irlandeses «Amergin»

Universidade da Coruña

doi:10.17075/mucnoc.2014.039 

Forcadela, M. / T. López / D. Vilavedra (coords.) (2014): Mil e un cunqueiros. Novas olladas para un centenario, Santiago de Compostela, Consello da Cultura Galega. doi:10.17075/mucnoc.2014. pp. 785-802

A pesar de todas as teorías desenvolvidas até o momento desde finais do século XIX cos Precursores á cabeza, Galicia segue á cola dos estudos célticos, debido, entre outros motivos, ao compoñente lingüístico que exclúe á cultura galega do ámbito en cuestión, xa que, desde o punto de vista filolóxico, a lingua galega non deriva do mesmo tronco que a irlandesa, escocesa ou galesa. Neste sentido, debemos retrotraernos á importancia dada ao criterio lingüístico (Berresford 1998; Payton 2000: 111), no que respecta á relación entre Galicia e o mundo celta, con graves consecuencias para a apertura de novas perspectivas neste campo. En primeiro lugar, consideramos que os académicos non fixeron esforzos significativos de achegamento a fenómenos celtas contemporáneos como a cultura popular ou as diásporas celtas (Hale e Payton 2000: 95). O segundo prexuízo céntrase no feito de que moitos territorios, cun conxunto menor ou limitado de literatura medieval, como Cornualles, a Illa de Man ou Galicia, foron marxinados ou ignorados polos críticos. Coa salvidade de recentes publicacións no ámbito internacional como os editados por Francis Boutle Publishers en Londres (Gibson e Griffiths 2009, de Toro 2010, Jennings e Marquis 2011).

Para algúns dos máis destacados intelectuais da época, o atlantismo e o celtismo supuxeron a renovación de anquilosados valores que enmarcaban a Galicia nun único marco posible: a península Ibérica. Escritores como Risco, nun incansable labor de reestruturación da cultura galega, revalidaron as teorías que Manuel Murguía ou Eduardo Pondal estableceran no século xix sobre a orixe do pobo galego. Mais, aínda que na actualidade a teoría do atlantismo de Risco non probe o pasado celta de Galicia para as nacións atlánticas, si que supón un nexo de unión indiscutible entre Galicia e outras nacións que envolven este océano (Lugrís 1963). A Galicia céltica postúlase como un referente de estudo publicado por Risco na revista Nós $(3,4$ e 5) e constitúe un proxecto enfocado á tarefa de rexeneración europea asignada á civilización atlántica. O Atlántico, que debería ser o Mare Nostrum dos celtas, encerraba no seu seo, cuberto polas augas, ese continente perdido de orixe descońecida, mais, non entanto, debía erguerse como símbolo do porvir e futuro do galeguismo. A teoría de Risco aínda ten 
seguidores que a utilizan fundamentalmente para marcar as diferenzas culturais que, segundo eles, se dan entre as dúas tendencias predominantes no Estado español: a oficial, de tendencia clásica/mediterránea, e a galega de tendencia céltica/ atlantista (Bobillo 1981).

Como fenómeno consecuente con esta identificación, algúns autores tentaron que a literatura galega confluíse, como sistema literario, xunto con outras literaturas «atlánticas» como a irlandesa, a escocesa, a galesa ou mesmo a americana $^{1}$. Todas elas, literaturas de fala inglesa e con visibles trazos do denominado atlantismo. Esta simbiose que xorde entre as literaturas dos países de fala inglesa e a literatura galega pódese interpretar en función das teses expostas por Pascale Casanova na súa obra La République mondiale des Lettres (1999), na que establece a interdependencia das literaturas periféricas con base nun fenómeno que dá lugar a unha fronte común de experiencias e realidades que supoñen unha alternativa ao canon literario oficial. Esta interdependencia literaria foi entendida por Risco como a construción da civilización atlántica, obrigada a un contacto estreito cos pobos que a integrarían. Risco atendeu preferentemente a dous: Portugal e Irlanda. En canto a Irlanda, era este un país clave na doutrina de Risco. O celtismo, base do Romanticismo idealista que o escritor galego lle asignaba á futura civilización atlántica, conxugábase cunha serie de factores que eran capitais no seu pensamento, o máis importante dos cales viña ser, sen dúbida, o tradicional catolicismo irlandés. Pero tamén a loita vitoriosa contra os ingleses e as relacións que a historiografía romántica establecera entre os dous países (Ó h-Éaluithe 2010).

Máis aló dos postulados que establece na súa obra Teoría do nazonalismo galego, Risco, a través do panceltismo e atlantismo, tamén establecerá o papel que xoga a terra para a comunidade cultural e literaria galega como un concepto ontolóxico, activo, orgánico, telúrico e, por extensión, vivo, que se verá reflectido en múltiples movementos nacionalistas e románticos ao longo e ancho de Europa e na creación das nacións-estado no século xix. A Terra, con maiúsculas, tal e como postulan estes ideólogos (véxase que o órgano de difusión das Irmandades da Fala se denomina $A$ Nosa Terra, con maiúsculas), dá lugar á ampliación das teorías célticas e románticas e á creación dun concepto maior que engloba a

1 Véxanse os escritores de Nova Inglaterra traducidos e descritos por Álvaro Cunqueiro como Edgar A. Poe ou E. Dickinson na tese de doutoramento (Jarazo 2009). 
todas as comunidades célticas: o panceltismo e o atlantismo. Os postulados máis importantes da súa ideoloxía son:

1. A civilización europea que tivo o seu berce no Mediterráneo, está a chegar ao seu fin.

2. A forza vital que ha de salvar a Europa desprazouse do Mediterráneo ao Atlántico.

3. As étnias mediterráneas, coa súa mestizaxe —xudios, mouros, etc.— contribuíron a esa decadencia. No Atlántico áchanse asentadas, pola contra, poboacións arias ás cales apenas chegou a mestizaxe. ("Eslavos e celtas")

4. As poboacións celtas atópanse en enclaves estratéxicos privilexiados da costa atlántica.

Ditas poboacións constitúen o sete nacións célticas: Highlands, Illa de Man, Irlanda, Gales, Cornwall, Bretańa e Galicia (Teoría do nazonalismo galego)

5. Estas nacións célticas —e Galicia con elas- han de porse á cabeza de Europa para lograr a súa reconstitución espiritual. ("Irlanda e Galicia" 18-21)

Porén, pouco despois de constituírse o Partido Galeguista en 1931, Risco verase excluído ideoloxicamente do Réxime imperante — a II República española. Xa ben por mor das súas posturas conservadoras, do seu catolicismo exacerbado ou o seu antisocialismo. Isto farao romper co seu ideario filosófico e ideolóxico anterior para adoptar outros carreiros ideolóxicos. Mais, en definitiva, o papel que xogan ideólogos como Vicente Risco ou Manuel Murguía é esencial para entender o celtismo, como corrente ideolóxica e estética, en Galicia. Influencia que terá o seu máximo expoñente na Xeración Nós ou en autores como Plácido Ramón Castro (Jarazo 2010a) e, posteriormente, Álvaro Cunqueiro, Castroviejo ou Valle-Inclán, e que chega aos nosos días, xa sexa para que escritores e ideólogos rexeiten os seus postulados estéticos e ideolóxicos, xa sexa para acollelos na súa obra ou ideoloxía. En calquera caso, non pode entenderse a situación da literatura e cultura galega actual se obviamos o marco cultural atlántico como resposta ao influxo cultural mediterráneo. Neste sentido, Álvaro Cunqueiro conforma un dos autores da xeración que constituíu o nexo de unión entre a Galicia da preguerra e a da posguerra civil a través dos cambios ideolóxicos que converxen na súa obra (Armesto 1987: 81; Franco 1991) e o paso do celtismo ao atlantismo.

Álvaro Cunqueiro é sobradamente coñecido por ser autor dunha gran produción literaria e xornalística fundamentada na reconstrución de mitos foráneos e a súa adaptación ao modelo galego (Tarrío 1989). Aínda que esta filosofía non 
é exclusiva das referencias e personaxes que se enmarcan na cultura dos países de fala inglesa (Rivera 2000), de igual xeito non debería resultar controvertido afirmar que o papel das correntes célticas en Cunqueiro xogan un papel especialmente relevante. Non esquezamos que algunhas das obras máis aclamadas por crítica e público do autor galego son Merlín e familia (1955), As crónicas do Sochantre (1956), e O incerto señor don Hamlet, principe de Dinamarca (1958), obras que se caracterizan por establecer fortes lazos entre a tradición cultural galega e a Materia de Bretańa —amálgama composta pola realidade cultural e literaria de Irlanda, Gales, Escocia, Cornualles, Inglaterra ou Bretaña. Neste sentido, existe unha extensa bibliografía que, dalgún xeito ou doutro, trata a fenomenoloxía do celtismo en aspectos moi concretos da produción de Cunqueiro (Ricci 1971; Pérez-Bustamante 1986; Jarazo 2005, 2006a, 2006b, 2007, 2009a, 2010b, 2010c, 2012).

Con todo, e a pesar de que a simple vista parece doado establecer as conexións célticas en Cunqueiro, este último nega a existencia do celtismo na súa obra tanto como movemento estético, como movemento de corte ideolóxico. Entre os múltiples exemplos de que dispomos, citamos quizais o máis clarificador e extenso a este respecto. A continuación, transcribimos parte da entrevista realizada a Álvaro Cunqueiro por Joaquín Soler Serrano en Radiotelevisión Española (http:// www. galiciadigital.com/opinion/opinion.357.php, transcrición da entrevista realizada en Televisión española e recollida por Fernando Andrade na páxina web Galicia Dixital):

\section{ENTREVISTADOR}

—La imaginación riquísima y la no menos rica prosa de Cunqueiro ha merecido el estudio de numerosos estudiantes de todo el mundo y hay infinidad de tesis, algunas de las cuales hemos traído aquí para mostrarles acerca de diversos aspectos de su obra. Aquí, por ejemplo, en esta tesis “celtismo y Magia en la Obra de Álvaro Cunqueiro", Universidad de Perugia.

\section{ÁLVARO CUNQUEIRO}

—Sí, un italiano llamado Carlo Ricci (?), discípulo de Giovanni Allegra, que ha sido lector de... 


\section{ENTREVISTADOR}

- Tremenda Tesis.

\section{ÁLVARO CUNQUEIRO}

- Sí, tremenda Tesis, sabe de mi más que yo y claro, bueno, la Tesis tiene un error importante de punto de partida que es, eso, lo que antes hablábamos del celtismo gallego.

\section{ENTREVISTADOR}

-Y esta es otra.

\section{ÁLVARO CUNQUEIRO}

—Ah, sobre "Las Mocedades de Ulises" de una chica de inglesa de la Universidad de Lich (?), Linda Shepherd (?), muy muy bien hecha, en fin, realmente...

\section{ENTREVISTADOR}

— ¿Cómo se ve Álvaro Cunqueiro a través de estas disecciones, de estos estudios exhaustivos? ÁLVARO CUNQUEIRO

-Sí, pues, con cier, con cierto, por ejemplo, en la tesis de Carlo Ricci esta de "Magia, imaginación y celtismo en la obra de Álvaro Cunqueiro" pues me cuesta mucho trabajo encontrarme porque evidentemente yo no encuentro para nada mi celtismo. En cambio, por ejemplo, en el de Linda veo que ella ha hecho un enorme esfuerzo para entender lo que para mí habría sido a los doce, o a los trece, o a los catorce ańos ir de grumete en una nave al descubrimiento de las islas de las islas griegas y como todos esos mitos de los helenos en mi han ocupado tanto, en mi alma han ocupado tanto espacio y condicionado tanto mi poder de evocación, sí» (Entrevista realizada a Álvaro Cunqueiro por Joaquín Soler Serrano en Radiotelevisión Española. Transcripción extraída de la web http://www.galiciadigital.com/ opinion/opinion.357.php). (Soler 2008)

Como podemos observar con total claridade nesta entrevista concedida, o autor nega radicalmente calquera achegamento cara ao celtismo. Chega a desprezar abertamente o celtismo como corrente válida para a creación da identidade galega. Non parece, con todo, que Cunqueiro renegue do posible valor estético desta corrente. Tal e como apunta de Toro en La literatura irlandesa en España: 
Escritores como Otero Pedrayo, Vicente Risco, Plácido Castro, que antes adoptaran una postura reivindicativa, ahora junto con Ramón Castroviejo, o Álvaro Cunqueiro evocan las tierras sońadas de Irlanda retrotrayéndose a la leyenda o a la representación imaginativa, todo esto envuelto en una atmosfera melancólica. [...] A diferencia del interés sentido por todo lo irlandés antes de la Guerra Civil, esta nueva aproximación descansaba mas bien en supuestos estéticos antes que en razones exclusivamente ideológicas (2007: 59).

Aínda que podemos falar da utilización do celtismo na súa obra como un trasfondo simplemente estético e non político, pola súa posición durante o réxime franquista (Armesto 1987: 131-9), o autor afirma, noutras entrevistas, que a utilización dos mitos son unha ferramenta para exercer unha crítica velada cara a un réxime ditatorial como o da posguerra española:

É curioso, pero durante a ocupación alemá de Francia, un francés púxose a traducir a Homero. Durante o franquismo Segarra, en Cataluña, traducía a Shakespeare e Riva a Homero. Cónstame que a censura, na tradución de Segarra, cargouse algúns parágrafos porque Shakespeare era moitas veces unha opinión política. Así pois, os clásicos son algunhas veces a maneira que ten un home para poder dicir cousas que non lle permite dicir unha situación sen moita liberdade de palabra (Outeiriño 1979: 12).

Vemos, polo tanto, á luz desta resposta, como Cunqueiro cre no valor dos mitos a modo de ferramenta de denuncia e ten moi presente o valor nas traducións de Shakespeare para o castelán, traducións das que volveremos dar conta posteriormente. Porén, Cunqueiro foi duramente criticado pola súa posición durante o réxime e o seu reflexo, a través dunha actitude evasionista, na súa obra literaria. Crítica, na nosa modesta opinión, bastante reducionista e simplista, tendo en conta que a literatura fantástica non é sinónimo de ausencia de crítica social.

Con todo e abandonando por un momento as teses enfrontadas que testemuñan a Cunqueiro como celtista convencido (Ricci 1971) ou como inimigo do celtismo (Alonso 2007), resulta innegable que, nunha primeira etapa, o escritor compartiu as teses ideoloxicamente ligadas ao celtismo establecidas pola Xeración Nós e á intelectualidade galega da época. A recepción e presenza dos países de fala inglesa na obra de Cunqueiro, parte inescusable do celtismo e as referencias á cultura irlandesa, escocesa ou galesa. Cunqueiro asimila correntes culturais como o atlantismo e o panceltismo, até que, anos máis tarde, se produce un posterior 
desencanto, o que se reflicte nas súas composicións literarias en prensa do mesmo xeito que na súa obra narrativa (Álvarez 2010). Cunqueiro, por múltiples motivos, entre eles, un xiro cara ás teses conservadoras do réxime franquista, sufrirá o que denominamos o desencanto do celtismo.

Mais aló da descrenza no celtismo que supón obras como El año del cometa con la batalla de cuatro reyes (1974) (Álvarez 2010) ou a ironía que lle insire a personaxes como dona Xenebra (Cunqueiro 1974: 200-1), a frivolización e descrédito dos personaxes artúricos da materia de Bretaña é continua, aínda que non constante, na produción periódica en prensa do autor galego. Un caso de estudo é a columna literaria «El Envés» no Faro de Vigo durante dúas décadas (Mera 2000, 2007; Jarazo 2009a), na que figuras como Arturo, o rei vingador eterno, perpetuo e futuro, é igualmente posto en entredito:

¿Y en apareciendo el cometa anunciará a Bretańa el regreso de Arturo? ¿A quién le anunciará el cometa el regreso de Cintolo? ¿Quién lo sabe? [...] Si el cometa es propicio, se estremecerán los huesos del rey, y acaso una terrible y majestuosa sombra se alce en el umbral de la caverna. Lo que no tendrá sentido si no quedan fieles suyos, aunque solamente lo sean de imaginación: si no quedan gentes que esperen la resurrección de un gran rey, capaz de presidir de nuevo la Edad de Oro. Como en Bretańa, Arturo, rey perpetuo y futuro. Pero nunca he oído de que haya una profecía suintiliana (Cunqueiro 1973: 26).

Polo tanto, a súa produción máis convencional non é a única que, como vemos, merece dun estudo pormenorizado. É aí onde entra en xogo a produción periódica do xenial escritor mindoniense. Varias son as razóns que desmereceron o traballo xornalístico de Cunqueiro en numerosas publicacións durante décadas, aínda que, quizais, a máis representativa fose a dificultade de catalogar e seleccionar unha obra periódica esparexida por España e parte de Latinoamérica, en ocasións, baixo o exercicio do pseudonimato. En verdade, como puidemos comprobar, moito se ten dito de Cunqueiro, pero pouco no ámbito do xornalismo, desde que no ano 1991, no que as Letras Galegas foron dedicadas ao escritor mindoniense (Armesto 1987, 1993a, 1993b; Filgueira 1991; Mera 2000, 2007; Jarazo 2009a).

A prensa periódica, marcada por unha época de precariedade, permite unha difusión cultural barata e accesible, á vez que escapa con maior facilidade á man 
censora. Mais non será posible unha tímida diversidade cultural en Galicia, até que non finalice o que Carlos Barrera denomina período de «diversificación política» da prensa, período estritamente posterior á Guerra Civil, no que os rotativos adquiren unicamente fins instrumentais e propagandísticos (Barrera 1995: 18).

Xa na década do sesenta, o aperturismo ficticio que o franquismo permitiu traerá consigo un aperturismo real na esfera da cultura con consecuencias que o réxime non divisou a curto prazo (Tusell 1991: 554). O auxe das editoriais e a aparición dos suplementos culturais será determinante neste proceso. Aínda que os rotativos constituían por aquel entón un instrumento propagandístico e de control ideolóxico, os anos da guerra quedan atrás e as noticias de corte política ceden certo espazo ás culturais e/ou literarias. Especialmente en Galicia, esta reactivación cultural vén da man do labor de editoriais como Galaxia, Edicións Xerais de Galicia ou Grial, entre as máis representativas do século xx.

Neste ámbito, tanto en Galicia como no resto de España, as literaturas foráneas, en especial as anglófonas, xogarán un papel decisivo. A recepción das mencionadas culturas na prensa periódica española e galega despois dos anos da guerra atenderá novamente a diversas motivacións estéticas e ideolóxicas, destacando o papel da cultura irlandesa en Galicia (de Toro 2007) e inglesa en Cataluña (Buffery 2007) fronte ao resto do territorio español. A cultura irlandesa non incide do mesmo xeito nas comunidades periféricas como Galicia, o País Vasco ou Cataluña, que no resto da Península. Estas comunidades verán en Irlanda e a súa independencia fronte ao Reino Unido un espello no que, en maior ou menor medida, os seus intelectuais quererán reflectirse. Pola contra, no resto da Península, Irlanda e o elemento céltico serán apreciados unicamente como un movemento ou tendencia estética e non ideolóxica, como pode ser o caso galego.

Durante estas décadas, un dos pioneiros na introdución da cultura irlandesa contemporánea é, xunto con Vicente Risco, Plácido Ramón Castro del Río (Jarazo 2010a). Castro, así mesmo, constituirase como precursor de Cunqueiro iniciando a tradición das traducións foráneas en xornais como o Faro de Vigo anos antes de que o mindoniense comezase o seu labor xornalístico no rotativo vigués (capítulo adicado á tradución de poesía anglófona no Suplemento Cultural de «Letras» en Jarazo 2009a; Jarazo 2012). Plácido Castro, a través das palabras veladas da tradución, propiciará en Galicia a apropiación de modelos e repertorios irlandeses para o sistema literario galego, xa que a tradución poética a este idioma, 
accesible tanto para ser traducida como publicada pola súa curta extensión, constitúe unha acción cultural que, en principio, non se revolve contra o status quo establecido polo franquismo e axuda no proceso de rexeneración e mantemento da cultura e literatura galegas.

En canto á produción de Álvaro Cunqueiro no Faro de Vigo, esta atende fundamentalmente a dúas décadas na columna literaria «El Envés» e ao Suplemento cultural de «Letras», coordinado este último en colaboración con Francisco Fernández del Riego. A columna literaria atende a un interese particular de Cunqueiro por informar continuadamente ao lector do «anverso» das noticias, tal como apunta Montserrat Mera (2000). O novidoso e interesante desta columna é a facilidade coa que as noticias actúan como vasos comunicantes co global da súa produción narrativa, teatral e poética. Esta característica é a que nos permitiu afondar na recepción das culturas anglófonas en «El Envés» e analizar o paso do celtismo cara ao atlantismo en Cunqueiro e o seu posterior desencanto. En «El Envés», Cunqueiro ensaia as súas obras, fabula, recrea outros mitos secundarios para a súa produción teatral ou narrativa e, polo tanto, constitúe unha lectura esencial para entender obras como Don Hamlet (Jarazo e Domínguez 2010a), "Función de Romeo e Xulieta» (Jarazo e Domínguez 2010b), Sueño de una noche de San Juan, El año del cometa (1974) ou Merlín e familia (1955).

Nesta columna literaria, Cunqueiro experimenta coa obra shakesperiana, deféndese de ataques públicos (Cunqueiro 1958: 25), implica o lector nos seus procesos creativos pero, quizais, o máis significativo é que nesta serie o escritor galego entretece unha marańa de referencias do estrato céltico creando, á súa vez, unha cosmogonía paralela á da súa produción narrativa centrada esencialmente nas figuras de Merlín, Xenebra, o rei Arturo, Lanzarote do Lago, Lady Macbeth (Jarazo 2006b) ou mesmo uns poemas apocalípticos galeses medievais. O autor, polo tanto, fai alarde dos seus cońecementos eruditos reproducindo en numerosas ocasiones trazos destes personaxes pertencentes a tradicións tan dispares como a irlandesa ou a galesa ou remontándose ao século XII. Neste sentido, facer referencia á Materia de Bretaña en Galicia e, en especial, a Merlín, supón obrigatoriamente facer referencia a Cunqueiro e, en gran medida, non só a obras como Merlín e familia ou El año del cometa, senón que parte deste mérito se debe á produción literaria en «El Envés», ao igual que noutros xornais como El Pro- 
greso de Lugo ou La Voz de Galicia entre outros ${ }^{2}$. Co paso dos anos, advírtese un cambio radical ante o celtismo e a Materia de Bretańa nesta columna literaria por parte do escritor galego. Aínda que as referencias á cultura irlandesa, escocesa ou galesa formarán parte da columna literaria até o final dos seus días, estas referencias actuarán simplemente como elementos para a caracterización dun personaxe (Cunqueiro 1964b: 16) ou como un simple recurso estético que lle permita ao escritor mindoniense achegarse a outro tema de actualidade (Cunqueiro 1973: 8).

O tratamento que confire, polo tanto, a estas referencias na súa produción narrativa, do mesmo xeito que na xornalística, irá en favor doutros intereses, motivación orixinada posiblemente polo desencanto do celtismo de don Álvaro, a súa obsesión pola persoa e obra de William Shakespeare (Cunqueiro 1964a) ou a apertura paulatina cara a un modelo capitalista e global, no que a cultura e literatura americanas cada vez ten máis relevancia nos espazos culturais da Península. Neste sentido, é de obrigado cumprimento facer referencia ao Suplemento Cultural de «Letras» do rotativo vigués.

O Suplemento Cultural de «Letras» do Faro de Vigo, artellado por Cunqueiro e Francisco Fernández del Riego, constitúe un exemplo do labor rexenerador destes dous literatos na cultura galega durante a posguerra española. Para aqueles que consideran a Álvaro Cunqueiro un autor conservador, ensimesmado no seu mundo imaxinario, deben ter en conta a importancia do Suplemento cultural durante dúas décadas na produción de Cunqueiro para mudaren de opinión. A tradución e asimilación ao sistema cultural galego de autores comprometidos coa causa republicana durante a guerra civil española como Langston Hughes, autores innovadores aínda que grotescos, como William Faulkner, homosexuais como Hart Crane, protofeministas como Elizabeth Barret Browning ou Virginia Woolf, suicidas como Sylvia Plath, divorciados como Ted Hughes, atormentados como Poe, reivindicativos como Padraic Colum, comprometidos con temáticas sociais como Sean O'Casey, heréticos como Walt Whitman ou William Blake, bohemios como Jack Kerouac ou Allen Ginsberg, exconvictos como Brendan Behan ou Gregory Corso, ou xudeus como Leonard Cohen, constitúe boa proba

2 Artigos e referencias recompiladas como parte do Proxecto «La influencia de la cultura anglosajona en la obra periodística de Álvaro Cunqueiro» Entidade financiadora: Excma. Deputación Provincial da Coruña. Entidades participantes: Instituto Universitario de estudos irlandeses Amergin, Universidade da Coruña (2006-7). 
da existencia dun Cunqueiro máis humano e comprometido coas causas sociais do seu tempo que o Cunqueiro conservador e evasivo ao que a crítica está afeita (Jarazo 2009a: 361-461).

O Suplemento Cultural de «Letras» do Faro de Vigo (1961-1981) constitúe un elemento rexenerador do sistema literario galego semana tras semana, no que son traducidos centos de poemas foráneos, entre os que destacan os pertencentes ás culturas anglófonas, introducidos tanto de man de Cunqueiro como de Francisco Fernández del Riego. Ambos os dous autores constitúen, dalgún xeito a través deste suplemento, unha antoloxía baixo o paraugas do rotativo vigués. Se entendemos, polo tanto, o Suplemento Cultural como unha antoloxía, esta vese determinada polo momento da súa publicación. En efecto, tanto a elección do material que se vai publicar como o propio proceso de tradución do material seleccionado dependen do tempo no que a antoloxía se concibe, se desenvolve e se transmite (Klein 1995: 57).

No proceso de transmisión, as antoloxías concíbense cunha finalidade específica que, en calquera caso, dependen tanto dos editores e tradutores como dos receptores ás que están dirixidas. Como afirma Klein, a intención e os lectores prospectivos dunha antoloxía determinan desde a selección do material que se vai antologar até a incorporación de ilustracións (Enríquez 2004: 67). No caso de Cunqueiro e del Riego, a finalidade do Suplemento será a rexeneración da literatura galega na posguerra a través da tradución e recensión de poetas e novelistas ingleses, escoceses, galeses, irlandeses ou americanos. Neste sentido, os poetas irlandeses, escoceses ou galeses traducidos para o Faro, ou composicións de carácter céltico, constituirán unha minoría nas páxinas do Suplemento de «Letras» (Jarazo 2012), deixando paso especialmente á tradución e recensión de escritores americanos e ingleses, moi especialmente na década dos anos setenta (Jarazo 2009a: 361-461). Isto atende, ou ben, ao que Francisco Fernández del Riego denomina nunha entrevista inédita concedida como «o interese por aquilo que estaba de actualidade» [a cultura e literatura americanas] (Entrevista concedida en Vigo en abril 2009) (Jarazo 2009b), ou ben, por un certo desencanto fronte ao celtismo clásico das teses de Risco, do que o escritor mindoniense se afastará drasticamente tras a Guerra Civil.

En definitiva, o argumento principal xira ao redor da aceptación dun modelo foráneo, o céltico, que permitiu aos membros dunha cultura como a galega 
identificárense e diferenciárense como comunidade. Co tempo, novos postulados como o atlantismo deron paso a unha nova oposición dialóxica entre a comunidade galega e o resto do Estado español (comunidades atlánticas fronte ás comunidades mediterráneas). Con todo, para Bourdieu e Even-Zohar, non se trata dun simple exercicio separatista, senón dunha solución de emerxencia, dun caso de vida ou morte por parte do sistema literario e cultural como o galego. Para Even-Zohar, a intelectualidade galega de finais do século XIX non dispuña de alternativa ningunha de rexeneración do sistema literario e cultural, o que os levará a asumiren as correntes célticas e as súas continuadoras como propias. Todo iso lévanos a expornos o papel dos repertorios e a súa conveniencia ideolóxica e política. Unha conveniencia discutible que, co paso dos séculos, se transforma en aceptable. É por iso que o celtismo e o atlantismo, aínda que superado ideoloxicamente desde as teorías raciais establecidas polos ideólogos europeos de comezos do século xx, e seguidas en Galicia por Manuel Murguía ou Vicente Risco, mudou sen complexos cara a unha Galicia que agora goza dunha saúde envexable no contexto cultural e literario europeo. Un claro exemplo desta metamorfose no tempo é a sufrida pola obra de Álvaro Cunqueiro, escritor que experimentará todas as etapas.

O celtismo en Cunqueiro, fonte inesgotable de novelas, obras teatrais e centos de artigos en prensa, resulta, polo tanto, un tema controvertido no autor. Agora ben, e no caso que nos ocupa, é innegable que na súa etapa máis céltica, por denominalo dalgún xeito, xa ben por condicionantes estéticos e combativos ou unicamente estéticos, ou ningún dos dous casos — como el mesmo afirma-, Cunqueiro érguese inconscientemente como fundador dunha estética moi particular na que se enmarca o celtismo actual, do que perfectamente poden ser herdeiros Manuel Rivas, Suso de Toro, Xosé Luís Méndez Ferrín ou Luz Pozo Garza. En palabras desta escritora, na súa obra As arpas de Iwerddon (2005), Galicia e as comunidades atlánticas constitúen unha entidade cultural única unidas entre si polas pontes construídas a través da palabra, o texto literario. Cunqueiro e os seus textos literarios constitúen esa ponte ou nexo de unión entre as primeiras xeracións, que viron no celtismo unha corrente ideolóxica coa que se identificaren fronte á cultura mediterránea oficialista do Estado español, e a modernidade sen complexos asentada na Galicia mais atlántica. 
Ben é certo que don Álvaro non estaría de acordo con estas afirmacións miñas, do mesmo xeito que non estaba de acordo coa tese de Ricci, cando este último analizaba o influxo do celtismo na súa obra. 


\section{REFERENCIAS BIBLIOGRÁFICAS}

Alonso Montero, Xesús: Escritores galegos ante a Guerra Civil española, Vigo, Galaxia, 2007.

Álvarez, Marta: «El año del cometa de Álvaro Cunqueiro: La evidente aventura del contar», Tese de outoramento, Universidade de Zúric, 2010.

Armesto Faginas, Xosé Francisco: Cunqueiro: unha biografia, Vigo, Edicións Xerais de Galicia, 1987.

Armesto Faginas, Xosé Francisco: "Cunqueiro periodista», en Congreso Álvaro Cunqueiro, Santiago de Compostela, Dirección Xeral de Cultura, 1993a, pp. 555-62.

Armesto Faginas, Xosé Francisco: «O Cunqueiro, periodista», en Araceli Herrero Figueroa et al. (eds.), Congresso A. Cunqueiro, Mondońedo, Servizo Publicacións Diputación Provincial de Lugo, 1993b, pp. 183-85.

Barrera, Carlos: Periodismo y franquismo. De la censura a la apertura, Barcelona, Ediciones Internacionales Universitarias, 1995.

Berresford, Peter: «Contemporary Innovations in Religion in Scotland», Keltria 27 (1998).

Bobillo, Francisco: Nacionalismo gallego. La ideología de Vicente Risco, Madrid, Akal Universitaria, 1981.

Buffery, Helena: Shakespeare in Catalan. Translating Imperialism, Cardiff, University of Wales Press, 2007. Casanova, Pascale: La Republique Mondiale des Lettres, París, Seuil, 1999.

Cunqueiro, Álvaro: «Hamlet y un anónimo», «El envés: columna literaria», Faro de Vigo, 1 xullo 1958, p. 25.

Cunqueiro, Álvaro: «As mil caras de Shakespeare», Grial 2.6 (1964a), pp. 419-36.

Cunqueiro, Álvaro: «Asuero en Praga y otras noticias», «El envés: columna literaria», Faro de Vigo, 25 marzo 1964 b, p. 16.

Cunqueiro, Álvaro: «Un muerto en Segesvar», «El envés: columna literaria», Faro de Vigo, 17 xan. 1973, p. 8.

Cunqueiro, Álvaro: «A la espera del cometa», «El envés: columna literaria», Faro de Vigo, 27 dec. 1973, p. 26.

Cunqueiro, Álvaro: El año del cometa con la batalla de los cuatro reyes, Barcelona, Ediciones Destino, 1974.

Enríquez Aranda, María Mercedes: «Análisis externo de las antologías de traducción españolas del romanticismo poético inglés (1915-2002)», Trans 8 (2004), pp. 61-74.

Filgueira Valverde, Xosé: «Álvaro Cunqueiro. O periodismo e o ensaio» El Correo Gallego, Santiago de Compostela, 17 maio 1991, n. pax.

Franco Grande, Xosé Luís: «Expulsión e readmisión do periodista Álvaro Cunqueiro» A Trabe de Ouro IV, 8 (1991), pp. 105-14.

Gibson, Jacqueline e Gwyn Griffiths (eds.): The Turn of the Ermine - a Bilingual Anthology of Breton Literature, Londres, Francis Boutle Publishers, 2009.

Hale, Amy e Philip Payton (eds.): New Directions in Celtic Studies, Exeter, University of Exeter Press, 2000. Jarazo Állvarez, Rubén e Elena Domínguez Romero: «El discurso shakesperiano en la cultura popular gallega: el papel de la prensa periódica de Álvaro Cunqueiro en "El Envés" (Faro de Vigo 1961-1981)", Espéculo 45 (2010a) (http://www.ucm.es/info/especulo/numero45/elenves.html 26/04/11).

Jarazo Álvarez, Rubén e Elena Domínguez Romero,: «Muerte, peste, hambre y miedo en una versión gallega de Romeo y Julieta», Garoza 10 (2010b), pp. 133-145.

JaRAZo Álvarez, Rubén: «Una introducción al mundo escocés en la obra de Álvaro Cunqueiro: El mito merlinés y su deuda con Escocia», en José Ángel Fernández Roca, Manuel Cousillas, Pablo Cancelo López et al. (eds.), Actas del III Congreso de la Sociedad Española de Estudios literarios de Cultura Popular (SELICUP), A Coruña, Servizo de Publicacións da Universidade da Coruña, 2005, pp. 695-706. 
Jarazo Álvarez, Rubén: «Galicia or the last Celtic debatable land», en Estudos Atlânticos. Novos rumos para uma matriz multidisciplinar circum-atlântica, Rianxo, Instituto Galego de Estudos de Segurança Internacional e da Paz / Tórculo Artes Gráficas, 2006a, pp. 123-137.

JARAzo Álvarez, Rubén: «Localización e identificación do simbolismo mitolóxico nun artigo de Álvaro Cunqueiro: Das Crónicas de Holinshed á loucura de Lady Macbeth», en El futuro de las humanidades, Ferrol, Servizo de Publicacións da Universidade da Coruña / Concello de Ferrol, 2006b, pp. 39-47.

Jarazo Álvarez, Rubén: "Un viaje a Irlanda en la literatura gallega: Lord Dunsany y Álvaro Cunqueiro», en Estudios Joyceanos en Gran Canaria: Joyce «in his Palms», Las Palmas de Gran Canaria, Huerga y Fierro Editores, 2007, pp. 153-166.

Jarazo Álvarez, Rubén: «La cultura de los países de habla inglesa en la obra periódica de Álvaro Cunqueiro en el Faro de Vigo (1961-1981)», Tese de doutoramento, Universidade da Coruńa, 2009a.

Jarazo Álvarez, Rubén: «Entrevista inédita a Francisco Fernández del Riego con motivo del Suplemento Cultural de "Letras" del Faro de Vigo", concedida en Vigo en abril, 2009b.

Jarazo Álvarez, Rubén: «Plácido R. Castro del Río e o xornalismo galego: Traducción e apropiación literaria na prensa galega do século XX», en Rosa Aneiros, Xosé López García, Victor F. Freixanes (eds.), Xornalistas con opinión. Vinte biografías, Vigo, Galaxia, 2010a, pp. 233-250.

Jarazo Álvarez, Rubén: «Génesis y evolución de la cultura popular (anglófila) en la prensa periódica española de la posguerra: El Suplemento Cultural del Faro de Vigo (1961-1981) bajo la dirección de Álvaro Cunqueiro y Francisco Fernández del Riego», en Jesús Cañas Murillo, Francisco Javier Grande Quejigo e José Roso Díaz (eds.), Literatura popular e identidad cultural. Estudios sobre folclore, literatura y cultura populares en el mundo occidental, Cáceres, Servicio de Publicaciones de la Universidad de Extremadura, 2010b. Jarazo Álvarez, Rubén: «La influencia de Thomas Malory y la figura de Merlín en la obra periódica de Álvaro Cunqueiro: Un caso de estudio», Oceánide 2 (2010b), Sociedad Española de Estudios Literarios de Cultura Popular SELICUP (http://oceanide.netne.net/articulos/art2-8.php).

Jarazo Álvarez, Rubén: «Irish Poetry in Faro de Vigo (1961-1981): Francisco Fernández del Riego and Álvaro Cunqueiro in the Galician newspaper», ABEI Journal. The Brazilian Journal of Irish Studies 12 (2012).

Jennings, Geraint e Yan Marquis (eds.): The Toad and the Donkey: An anthology of Norman Literature from the Channel Islands, Londres, Francis Boutle Publishers, 2011.

KLeIN, Holger: «Anthologies of German Poetry in Translation Published in Britain 1930-1990», en Harald Kittel (ed.), International Anthologies of Literature in Translation, Berlín, Erich Shmidt, 1995, pp. 56-83.

Lugrís, Ramón: Vicente Risco na cultura galega, Vigo, Xerais, 1963.

Mera Fernández, Montserrat: "Álvaro Cunqueiro: la necesidad de informar sobre el envés de la actualidad», Estudios sobre el mensaje periodístico 6 (2000) Universidad Complutense de Madrid (http://www.ucm.es/ info/emp/Numer_06/6-4-Inve/6-4-05.htm 26/04/11).

Mera Fernández, Montserrat: El periodismo de Álvaro Cunqueiro, Lugo, Deputación Provincial, 2007.

OuteIrIÑo, Maribel: «Soy un antimarxista visceral», Región 8 (1979), p. 12.

ÓH-ÉALuithe, Adrian: «Beara — Breifne_ Compostela: derrota, huida y exilio de la nobleza de Munster», Oceánide 2 (2010), Sociedad Espańola de Estudios Literarios de Cultura Popular SELICUP (http:// oceanide.netne.net/articulos/art2-1.php).

Payton, Philip: «Re-inventing Celtic Australia», en Amy Hale e Philip Payton (eds.), New Directions in Celtic Studies, Exeter, U. of Exeter P., 2000, pp. 108-125. 
Pérez-Bustamante Mourier, Ana Sofía: «La narrativa mítica de Álvaro Cunqueiro», Tese de doutoramento, n. pax., 1986.

Pozo Garza, Luz: As arpas de Iwerddon, Santiago de Compostela, Linteo, 2005.

RICCI, Carlo: «Celtismo e magia n'ella opera de Álvaro Cunqueiro», Tese de doutoramento, Universidade de Perugia, 1971.

Risco, Vicente: «Teoría do nazonalismo galego», A Nosa Terra, 20 xullo 1918, n. pax.

Risco, Vicente: «Irlanda e Galicia», Nós (8), 5 dec. 1921, pp. 18-21.

Risco, Vicente: «Eslavos e celtas», A Nosa Terra 154, 31 dec. 1931, n. pax.

Rivera Pedredo, Dorinda: «Cultura y literatura italianas en la obra de Álvaro Cunqueiro», Tese de doutoramento, Universidade da Coruńa, 2000.

Soler Serrano, Joaquín: «Entrevista con Álvaro Cunqueiro en televisión española», Galicia Digital. 2001 (http://www.galiciadigital.com/opinion/opinion.357.php 25 ene 2008).

Spitzmesser, Ana: Álvaro Cunqueiro: La fabulación del Franquismo, Sada, Ediciós do Castro, 1995.

Tarrío Varela, Anxo: Álvaro Cunqueiro ou os disfraces da melancholia, Vigo, Galaxia, 1989.

Toro Santos, Antonio Raúl de e David Clark (eds.): British and Irish Writers in the Spanish Periodical Press 1900-1965, A Coruña, Netbiblo, 2007.

Toro Santos, Antonio Raúl de (ed.): La literatura irlandesa en España, A Coruña, Netbiblo, 2007.

Toro Santos, Antonio Raúl de (ed.): Breogán's Lighthouse: An Anthology of Galician Literature, Londres, Francis Boutle Publishers, 2010.

TusELL, Javier: Historia politica y social moderna y contemporánea, Madrid, UNED, 1991. 